\title{
Designing New Metal Chalcogenide Nanoclusters Through Atom-by-Atom Substitution
}

Habib Ghoilpour-Ranjbar, ${ }^{a}$ Hong Fang, ${ }^{b}$ Jintong Guan, ${ }^{c, b}$ D Angelo Peters, ${ }^{a \dagger}$ Audra Seifert, ${ }^{a \dagger}$ Puru Jena $^{b *}$, and Julia Laskin ${ }^{a *}$

${ }^{a}$ Department of Chemistry, Purdue University, West Lafayette, IN, 47906 USA

${ }^{b}$ Department of Physics, Virginia Commonwealth University, Richmond, VA, 23284, USA

${ }^{c}$ Department of Applied Physics and Institution of Energy and Microstructure, Nanjing University of Science and Technology, Nanjing, Jiangsu 210094, P. R. China

Correspondence to: jlaskin@purdue.edu, pjena@vcu.edu

Keywords: Cobalt sulfide cluster, atom-by-atom substitution, superatom, mass spectrometry

\footnotetext{
${ }^{\dagger}$ Undergraduate student researcher
} 


\begin{abstract}
Atom-by-atom substitution is a promising strategy for designing new cluster-based materials. Due to challenges associated with the synthesis and purification, this approach has been achieved only for a handful of gold and silver clusters. Here, we report the first study focused on atom-byatom substitution of $\mathrm{Fe}$ and $\mathrm{Ni}$ to the core of a well-defined cobalt sulfide superatom ligated with triethylphosphine, $\left[\mathrm{Co}_{5} \mathrm{MS}_{8}\left(\mathrm{PEt}_{3}\right)_{6}\right]^{+}(\mathrm{M}=\mathrm{Fe}, \mathrm{Ni})$. Electrospray ionization mass spectrometry confirms the substitution of 1-6 Fe atoms with the single Fe-substituted cluster being the dominant species. The Fe-substituted clusters oxidize in solution to generate dicationic species. In contrast, only a single Ni-substituted cluster is observed, which remains stable as a singly charged species. Collision-induced dissociation experiments indicate the reduced stability of the $\left[\mathrm{Co}_{5} \mathrm{FeS}_{8}\left(\mathrm{PEt}_{3}\right)\right]^{+}$ towards ligand loss in comparison with the unsubstituted and Ni-substituted counterparts. Density functional theory calculations provide insights into the effect of metal atom substitution on the electronic structures of the clusters. Our results indicate that $\mathrm{Fe}$ and $\mathrm{Ni}$ have a different impact on the electronic structure, optical and magnetic properties, as well as ligand-core interaction of $\left[\mathrm{Co}_{6} \mathrm{~S}_{8}\left(\mathrm{PEt}_{3}\right)_{6}\right]$. This study extends the atom-by-atom substitution strategy to the metal chalcogenide superatoms providing a direct path toward designing novel atomically precise coretailored superatoms.
\end{abstract}




\section{Table of content}

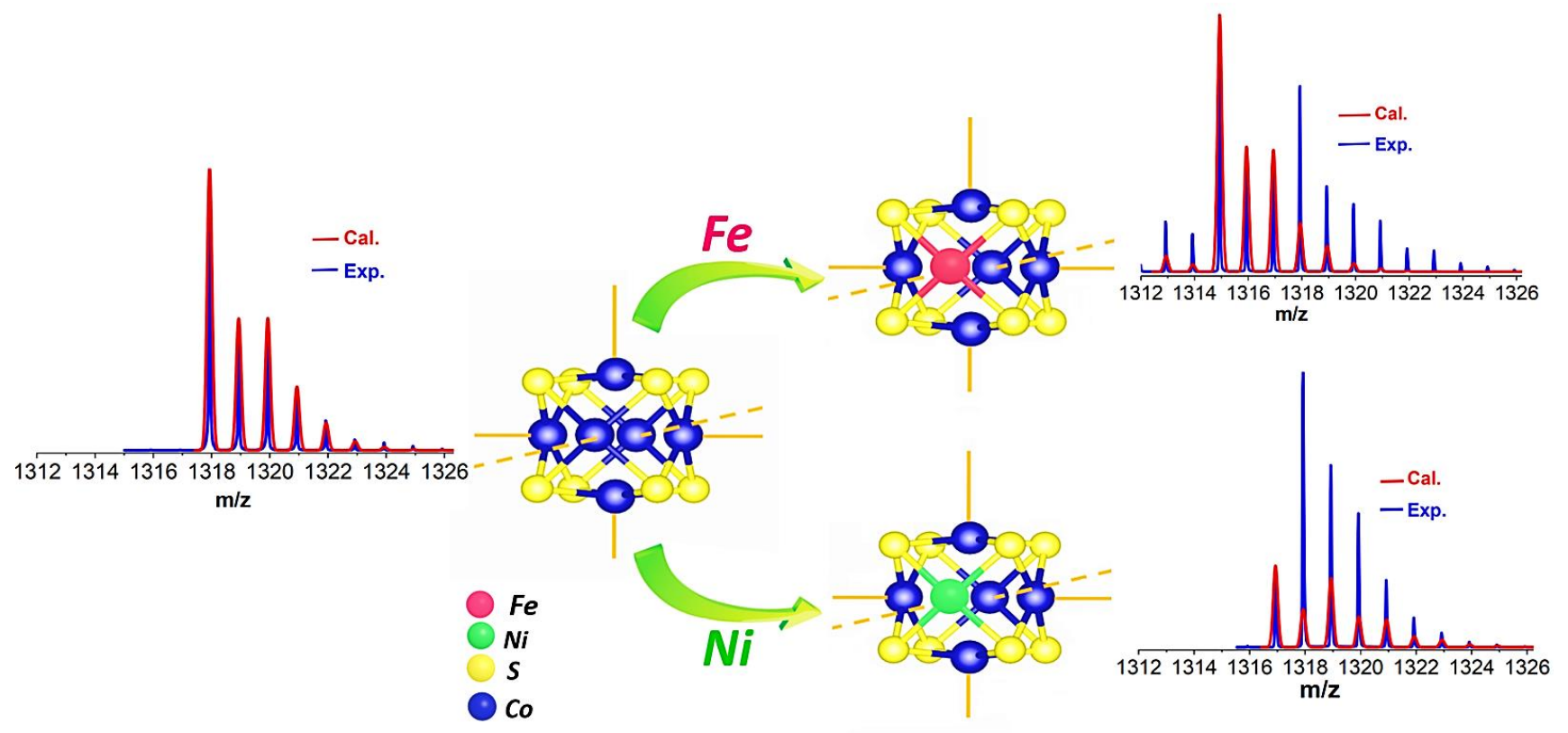




\section{Introduction}

Atomically-precise nanoclusters (NCs) have attracted considerable attention as unique building blocks for novel materials of interest to catalysis, energy storage, nanophotonics, sensing, and medical diagnostics. ${ }^{[1-5]}$ Most of the NCs are composed of a core and surface ligands. The core determines the overall characteristics of the cluster ${ }^{[6],[7]}$ while ligands enable fine-tuning of its properties and protect clusters from aggregation. ${ }^{[8],[9]}$ Atom-by-atom substitution is a promising strategy for further tuning the properties and structures of NCs for the generation of new clusterassembled materials. ${ }^{[10]}$ This process, which enables selective modification of the cluster core has been recently explored by several groups as an alternative approach to the more commonly used ligand exchange for tailoring the properties of NCs. ${ }^{[11]}$ However, progress in this field has been hindered by difficulties in both synthesis and purification of NCs for their characterization using X-ray crystallography. ${ }^{[1]}$ As a result, only a handful of core-tailored atomic clusters have been reported so far. ${ }^{[12],[13]}$ The first core-tailored cluster $\left(\mathrm{Au}_{24} \mathrm{Pd}_{1}\right)$ was synthesized by Murray's group. ${ }^{[14]}$ In that study, the substitution of a single $\mathrm{Pd}$ atom to the core of a $\mathrm{Au}_{25}$ cluster was confirmed using mass spectrometry. It has been demonstrated that substitution of a single Pd atom has a pronounced effect on the electronic and optical properties of the cluster. ${ }^{[9],[15],[16]}$ Several other gold and silver clusters have been subsequently modified using atom-by-atom substitution to the cluster core, ${ }^{[12-15]}$ generating NCs with improved catalytic and electronic properties. ${ }^{[17]}$

Herein, we extend the atom-by-atom substitution strategy to ligated metal chalcogenide clusters. Due to their redox activity, electrochemical stability, and unique magnetic properties ${ }^{[18]}$ these NCs have recently attracted attention as superatomic building blocks for the assembly of novel materials, ${ }^{[19],[20]}$ fabrication of energy storage devices, ${ }^{[18],[21]}$ and field effect transistors. ${ }^{[22]}$ The ability to tailor the electronic properties of these species using atom-by-atom substitution will lead to generation of novel functional clusters with tailored properties, expand the range of their applications, and provides a detailed understanding of the effect of atomic doping on the structureproperty relationships of metal chalcogenide NCs.

In this study, we examine metal substitution to the core of a cobalt sulfide cluster ligated with triethylphosphine, $\left[\mathrm{Co}_{6} \mathrm{~S}_{8}\left(\mathrm{PEt}_{3}\right)_{6}\right]$. This is a widely-studied metal chalcogenide superatom with a $\left[\mathrm{Co}_{6} \mathrm{~S}_{8}\right]$ core composed of an octahedron of cobalt atoms contained within a cube of face- 
capping sulfide atoms. ${ }^{[23-26]} \mathrm{Fe}$ and $\mathrm{Ni}$ atom-doped cobalt sulfide clusters, $\left[\mathrm{Co}_{5} \mathrm{M}_{1} \mathrm{~S}_{8}\left(\mathrm{PEt}_{3}\right)_{6}\right]^{+}$ $(\mathrm{M}=\mathrm{Fe}, \mathrm{Ni})$, are synthesized in methanol solution at room temperature. High-resolution electrospray ionization mass spectrometry (ESI-MS) confirms the substitution of either single Fe or $\mathrm{Ni}$ atom into the $\left[\mathrm{Co}_{6} \mathrm{~S}_{8}\right]$ core. Density functional theory (DFT) calculations indicate that the substitution of a single $\mathrm{Co}$ atom with $\mathrm{Fe}$ or $\mathrm{Ni}$ has only a minor effect on the structure of the core. In contrast with the Ni-doped cluster, for which only a single-atom substitution is observed experimentally, Fe substitution generates a distribution of Fe-doped clusters containing 1-6 Fe atoms. By examining the stability of the doped clusters, we observe that all the Fe-doped clusters tend to lose a second electron to generate doubly charged ions. In contrast, both the precursor cobalt sulfide cluster and its Ni-substituted analog remain stable as singly charged species. This is consistent with the calculated molecular orbital diagrams, which show that the highest occupied molecular orbital (HOMO) of the $\left[\mathrm{Co}_{5} \mathrm{FeS}_{8}\left(\mathrm{PEt}_{3}\right)_{6}\right]^{+}$is higher in energy than the HOMO of $\left[\mathrm{Co}_{5} \mathrm{NiS}_{8}\left(\mathrm{PEt}_{3}\right)_{6}\right]^{+}$and $\left[\mathrm{Co}_{6} \mathrm{~S}_{8}\left(\mathrm{PEt}_{3}\right)_{6}\right]^{+}$. Additionally, electronic structure calculations for the clusters show that the energy gap between the HOMO and the lowest unoccupied molecular orbital (LUMO) decreases following the substitution of $\mathrm{Co}$ with $\mathrm{Ni}$ or Fe. This finding indicates that the optical properties of the cluster change noticeably as a result of $\mathrm{Ni}$ and $\mathrm{Fe}$ atom substitution. Finally, using collision-induced dissociation (CID) experiments we demonstrate that substitution of a single $\mathrm{Co}$ with $\mathrm{Fe}$ in the $\left[\mathrm{Co}_{6} \mathrm{~S}_{8}\right]$ core substantially lowers the binding energy of the first ligand, which is consistent with the elongated Fe-P bond in comparison with $\mathrm{Co}-\mathrm{P}$ and $\mathrm{Ni}-\mathrm{P}$ bonds predicted by theory. These findings demonstrate a pronounced impact of a single-heteroatom substitution on the properties of the ligated cobalt sulfide superatomic cluster and open pathway towards designing superatomic NCs with enhanced optical, magnetic, and catalytic performance.

\section{Results and discussion}

The cobalt sulfide cluster sample synthesized as described in the experimental section is analyzed using high resolution quadrupole time of flight mass spectrometry (QTOF MS). Figure 1a shows a typical electrospray ionization (ESI) mass spectrum of the solution one day after the synthesis. The spectrum exhibits a strong peak at $m / z 1317.922$ corresponding to [Co6 $\left.\mathrm{S}_{8}\left(\mathrm{PEt}_{3}\right)_{6}\right]^{+}$. The spectrum also contains a small peak at $\mathrm{m} / \mathrm{z}$ 658.484, which corresponds to $\left[\mathrm{Co}_{6} \mathrm{~S}_{8}\left(\mathrm{PEt}_{3}\right)_{6}\right]^{2+}$. The accurate mass measurement and excellent match between the experimental 
and calculated isotopic patterns (inset in Figure 1a) of the cluster confirm this assignment. The mass spectrum of the sample acquired in negative ion mode (Figure S2) does not contain any peaks associated with cobalt sulfide species.

The ESI mass spectrum of the Ni-doped sample synthesized with 1:1 molar ratio of $\mathrm{CoCl}_{2}$ to $\mathrm{NiCl}_{2}$ shown in Figure $1 \mathrm{~b}$ contains two abundant peaks corresponding to $\left[\mathrm{Co}_{6} \mathrm{~S}_{8}\left(\mathrm{PEt}_{3}\right)_{6}\right]^{+}$and $\left[\mathrm{Co}_{5} \mathrm{NiS}_{8}\left(\mathrm{PEt}_{3}\right)_{6}\right]^{+}$at $\mathrm{m} / z \quad 1317.925$ and 1316.929, respectively. The isotopic pattern of $\left[\mathrm{Co}_{5} \mathrm{NiS}_{8}\left(\mathrm{PEt}_{3}\right)_{6}\right]^{+}$overlaid with the experimental spectrum shown in the inset of Figure $1 \mathrm{~b}$ confirms the presence of both species in the sample solution. No doubly charged species are observed in the spectrum and only a single Ni atom substitution could be achieved over a broad range of the synthesis conditions examined in this study. In contrast to the Ni-doped sample, the ESI mass spectrum of the Fe-doped sample synthesized with a $1: 1$ molar ratio of $\mathrm{CoCl}_{2}$ to $\mathrm{FeCl}_{2}$ after one day (Figure 1c) exhibits the signal of $\left[\mathrm{Co}_{6} \mathrm{~S}_{8}\left(\mathrm{PEt}_{3}\right)_{6}\right]^{+}$at $m / z$ 1317.922, and a distribution of Fe-substituted clusters containing 1-6 Fe atoms with the single Fe-doped cluster being the dominant species. The peaks at $m / z$ 1314.924, 1311.925, and 1308.928 correspond to $1-3$ Fe-atom substituted clusters, respectively. The calculated isotopic pattern of $\left[\mathrm{Co}_{5} \mathrm{FeS}_{8}\left(\mathrm{PEt}_{3}\right)_{6}\right]^{+}$shown in the inset of Figure 1c confirms the presence of several overlapping isotopic distributions in this $\mathrm{m} / \mathrm{z}$ range, which further corroborates the assignments. Moreover, we observe abundant peaks in the $m / z$ range of 650-660, which correspond to doubly charged Fe-doped clusters including $\left[\mathrm{Co}_{5} \mathrm{FeS}_{8}\left(\mathrm{PEt}_{3}\right)_{6}\right]^{2+}, \quad\left[\mathrm{Co}_{4} \mathrm{Fe}_{2} \mathrm{~S}_{8}\left(\mathrm{PEt}_{3}\right)_{6}\right]^{2+}, \quad\left[\mathrm{Co}_{3} \mathrm{Fe}_{3} \mathrm{~S}_{8}\left(\mathrm{PEt}_{3}\right)_{6}\right]^{2+}, \quad\left[\mathrm{Co}_{2} \mathrm{Fe}_{4} \mathrm{~S}_{8}\left(\mathrm{PEt}_{3}\right)_{6}\right]^{2+}$, $\left[\mathrm{CoFe}_{5} \mathrm{~S}_{8}\left(\mathrm{PEt}_{3}\right)_{6}\right]^{2+}$, and $\left[\mathrm{Fe}_{6} \mathrm{~S}_{8}\left(\mathrm{PEt}_{3}\right)_{6}\right]^{2+}$ at $m / z$ 657.463, 655.964, 654.465, 652.966, 651.466, and 649.968, respectively. We note that $\left[\mathrm{Co}_{2} \mathrm{Fe}_{4} \mathrm{~S}_{8}\left(\mathrm{PEt}_{3}\right)_{6}\right],\left[\mathrm{CoFe}_{5} \mathrm{~S}_{8}\left(\mathrm{PEt}_{3}\right)_{6}\right]$, and $\left[\mathrm{Fe}_{6} \mathrm{~S}_{8}\left(\mathrm{PEt}_{3}\right)_{6}\right]$ are only observed as doubly charged species. These results indicate that as the number of Fe atoms in the cluster core increases, it becomes easier to oxidize the cluster to the +2 -charge state. 


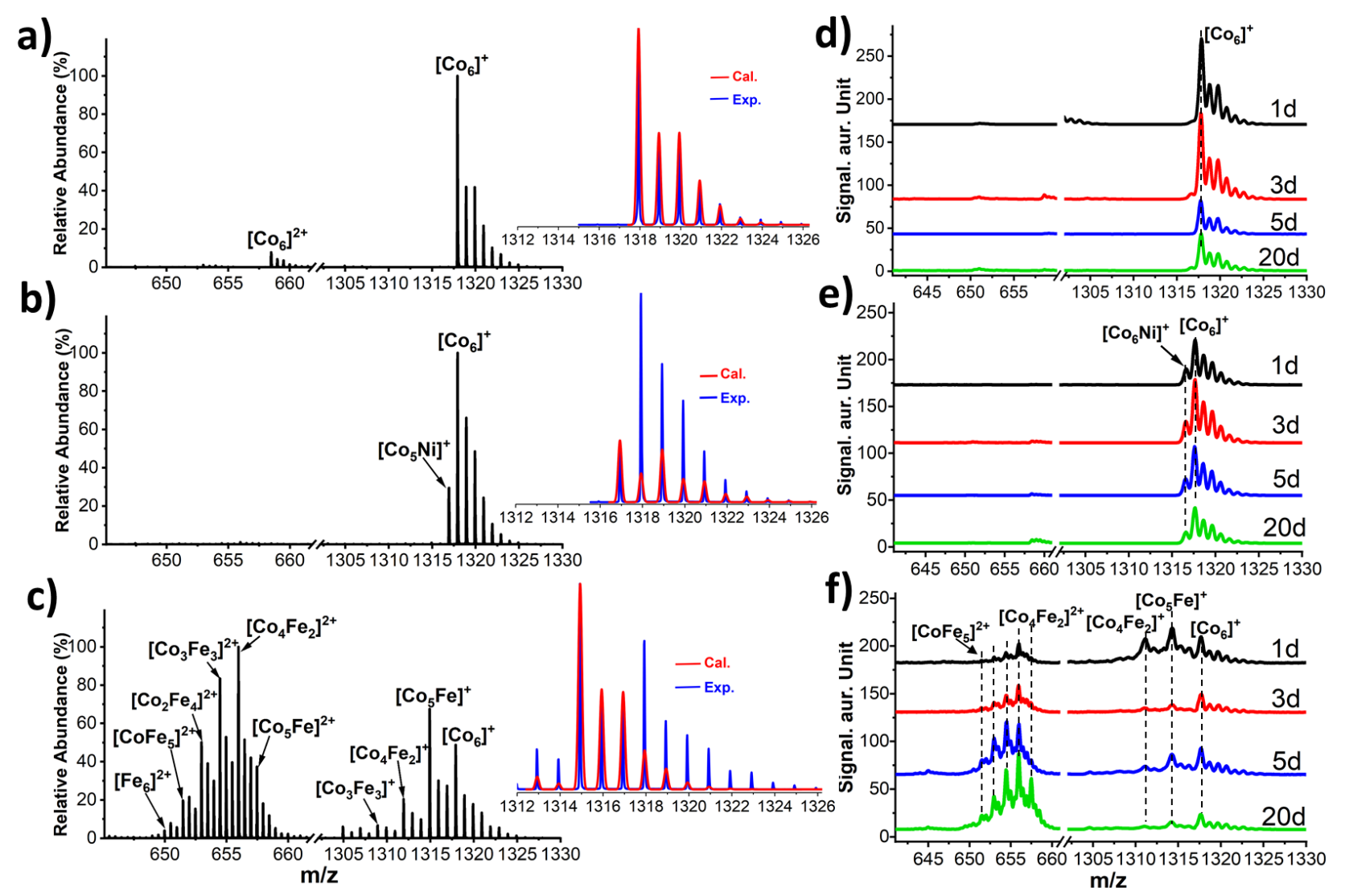

Figure 1.ESI mass spectra obtained in positive ion mode using high resolution QTOF MS for (a) cobalt sulfide cluster, $\left[\mathrm{Co}_{6} \mathrm{~S}_{8}\left(\mathrm{PEt}_{3}\right)_{6}\right]^{+}$, (b) Ni-doped cluster, $\left[\mathrm{Co}_{5} \mathrm{NiS}_{8}\left(\mathrm{PEt}_{3}\right)_{6}\right]^{+}$, (c) Fe-doped cluster, $\left[\mathrm{Co}_{5-\mathrm{x}} \mathrm{Fe}_{\mathrm{x}} \mathrm{S}_{8}\left(\mathrm{PEt}_{3}\right)_{6}\right]^{+}$. The insets show the calculated isotopic patterns of $\left[\mathrm{Co}_{6} \mathrm{~S}_{8}\left(\mathrm{PEt}_{3}\right)_{6}\right]^{+}$, $\left[\mathrm{Co}_{5} \mathrm{FeS}_{8}\left(\mathrm{PEt}_{3}\right)_{6}\right]^{+},\left[\mathrm{Co}_{5} \mathrm{NiS}_{8}\left(\mathrm{PEt}_{3}\right)_{6}\right]^{+}$overlaid with the experimental spectra in panels (a), (b), and (c), respectively. (d) ESI mass spectra of $\left[\mathrm{Co}_{6} \mathrm{~S}_{8}\left(\mathrm{PEt}_{3}\right)_{6}\right]^{+}$, (e) $\left[\mathrm{Co}_{5} \mathrm{NiS}_{8}\left(\mathrm{PEt}_{3}\right)_{6}\right]^{+}$, and (f) $\left[\mathrm{Co}_{5}\right.$ $\left.{ }_{x} \mathrm{Fe}_{x} \mathrm{~S}_{8}\left(\mathrm{PEt}_{3}\right)_{6}\right]^{+}$all in positive ion mode after 1, 3, 5, and 20 days, acquired using LTQ MS.

ESI mass spectra of the doped clusters synthesized using a lower molar ratio of the doping metal (e.g. 6:1 molar ratio of $\mathrm{CoCl}_{2} / \mathrm{FeCl}_{2}$ and $\mathrm{CoCl}_{2} / \mathrm{NiCl}_{2}$ ) are shown in Figure $\mathrm{S} 3$. The cluster distributions obtained under these conditions are similar to the ones shown in Figures 1(b,c), indicating that changing the molar ratio of the precursor metals does not affect the distribution of the final products. Collectively, our experimental results confirm the substitution of a single $\mathrm{Ni}$ atom and 1-6 Fe atoms into the core of the $\left[\mathrm{Co}_{6} \mathrm{~S}_{8}\left(\mathrm{PEt}_{3}\right)_{6}\right]^{+}$.

The stability of the synthesized cluster solutions over the course of twenty days is summarized in Figures 1d-f. ESI mass spectra of the cobalt sulfide cluster solution acquired using LTQ-MS 
(Figure 1d) contain an abundant peak at $m / z 1317.8$ indicating that $\left[\mathrm{Co}_{6} \mathrm{~S}_{8}\left(\mathrm{PEt}_{3}\right)_{6}\right]^{+}$is stable in the methanol solution even after twenty days. The Ni-doped cluster also remains stable in solution over twenty days (Figure1e). In contrast, the abundance of peaks corresponding to the singly charged Fe-doped clusters (Figure 1f) in the $m / z$ range of 1310-1317 decreases over time and at the same time the signals of the doubly charged species in the $m / z$ range of 650-660 become more abundant. This finding is consistent with the results obtained using QTOF MS (Figure 1c) and further confirms the higher propensity of the Fe-doped clusters toward oxidation in solution. Moreover, it is consistent with the lower oxidation potentials of $\left[\mathrm{Fe}_{6} \mathrm{~S}_{8}\left(\mathrm{PEt}_{3}\right)_{6}\right]$ in comparison with $\left[\mathrm{Co}_{6} \mathrm{~S}_{8}\left(\mathrm{PEt}_{3}\right)_{6}\right]$ reported in the literature and summarized in Table $1 .^{[27,[28]}$ We note that $\left[\mathrm{Fe}_{6} \mathrm{~S}_{8}\left(\mathrm{PEt}_{3}\right)_{6}\right]$ is particularly stable as a dication. ${ }^{[28-30]}$ This is consistent with its lower redox potential in comparison with $\left[\mathrm{Co}_{6} \mathrm{~S}_{8}\left(\mathrm{PEt}_{3}\right)_{6}\right]$, which is typically synthesized in its neutral form or as a singly charged cation. ${ }^{[27],[31]}$ Although the redox properties of the Fe-doped clusters have not been previously reported, the formation of the doubly charged $\left[\mathrm{Co}_{5} \mathrm{FeS}_{8}\left(\mathrm{PEt}_{3}\right)_{6}\right]^{2+}$ species indicates that the substitution of a single Co atom with Fe in the $\left[\mathrm{Co}_{6} \mathrm{~S}_{8}\right]$ core has a pronounced impact on the redox properties of the cluster.

Table 1. First, second, and third oxidation potentials (in V vs. SCE) of $\mathrm{Co}_{6} \mathrm{~S}_{8}\left(\mathrm{PEt}_{3}\right)_{6}$ and $\mathrm{Fe}_{6} \mathrm{~S}_{8}\left(\mathrm{PEt}_{3}\right)_{6}$ measured by cyclic voltammetry in dichloromethane.

\begin{tabular}{ccccc}
\hline Cluster & \multicolumn{3}{c}{ Oxidation potentials } & \\
& $0 / 1+$ & $1+/ 2+$ & $2+/ 3+$ & Ref \\
\hline \hline$\left[\mathrm{Co}_{6} \mathrm{~S}_{8}\left(\mathrm{PEt}_{3}\right)_{6}\right]$ & -0.48 & +0.37 & +1.13 & ${ }^{[27]}$ \\
{$\left[\mathrm{Fe}_{6} \mathrm{~S}_{8}\left(\mathrm{PEt}_{3}\right)_{6}\right]$} & -1.03 & +0.06 & +0.8 & ${ }^{[28]}$ \\
\hline
\end{tabular}

Our experimental results prove that the substituted species retain the same number of atoms in the core of the cluster and six surface ligands, indicating that atom-by-atom substitution to the core of cobalt sulfide superatom does not destroy its initial structure. This assertion is confirmed using DFT calculations of the structures of $\left[\mathrm{Co}_{6} \mathrm{~S}_{8}\left(\mathrm{PEt}_{3}\right)_{6}\right]$ and $\left[\mathrm{Co}_{5} \mathrm{MS}_{8}\left(\mathrm{PEt}_{3}\right)_{6}\right](\mathrm{M}=\mathrm{Fe}, \mathrm{Ni})$ clusters. In Figures 2(a-c) we present the equilibrium geometries of the $\left[\mathrm{Co}_{6} \mathrm{~S}_{8}\left(\mathrm{PEt}_{3}\right)_{6}\right]$, $\left[\mathrm{Co}_{5} \mathrm{FeS}_{8}\left(\mathrm{PEt}_{3}\right)_{6}\right]$, and $\left[\mathrm{Co}_{5} \mathrm{NiS}_{8}\left(\mathrm{PEt}_{3}\right)_{6}\right]$ clusters, which confirm that both of the clusters retain an octahedral core similar to the one of $\left[\mathrm{Co}_{6} \mathrm{~S}_{8}\left(\mathrm{PEt}_{3}\right)_{6}\right]$. This finding indicates that the core is largely unperturbed by the single substitution of Co by Fe or Ni. Computational studies also reveal that the energy cost for replacing 
a $\mathrm{Co}$ atom with $\mathrm{Fe}$ atom is lower than the $\mathrm{Ni}$ atom, which could rationalize the extensive $\mathrm{Fe}$ atomsubstitution to the core of the cluster observed experimentally. For example, our calculations show that it costs $0.31 \mathrm{eV}$ to replace a Co atom in $\left[\mathrm{Co}_{6} \mathrm{~S}_{8}\left(\mathrm{PEt}_{3}\right)_{6}\right]$ with an Fe atom, while the cost of replacing Co with $\mathrm{Ni}$ is three times higher, namely, $0.88 \mathrm{eV}$.

A striking experimental observation is the facile oxidation of Fe-doped clusters, which seems counter intuitive as the $\left[\mathrm{Co}_{5} \mathrm{FeS}_{8}\right]$ core has one less electron and the $\left[\mathrm{Co}_{5} \mathrm{NiS}_{8}\right]$ core has one more electron than the $\left[\mathrm{Co}_{6} \mathrm{~S}_{8}\right]$ core. It has been demonstrated that redox potentials of metal-sulfide clusters in solution are correlated to the HOMO energies of the corresponding gas-phase species. ${ }^{[32]}$ The calculated HOMO energy levels of the clusters examined in this study are summarized in Table 2. In the neutral state, the highest HOMO energy is observed for the $\left[\mathrm{Co}_{5} \mathrm{NiS}_{8}\left(\mathrm{PEt}_{3}\right)_{6}\right]$ cluster. However, in the +1 charge state, the HOMO level of this cluster is only slightly higher than that of the unsubstituted $\left[\mathrm{Co}_{6} \mathrm{~S}_{8}\left(\mathrm{PEt}_{3}\right)_{6}\right]^{+}$species. Meanwhile, the HOMO level of the cationic $\left[\mathrm{Co}_{5} \mathrm{FeS}_{8}\left(\mathrm{PEt}_{3}\right)_{6}\right]^{+}$cluster is higher than the values obtained for both $\left[\mathrm{Co}_{6} \mathrm{~S}_{8}\left(\mathrm{PEt}_{3}\right)_{6}\right]^{+}$ and $\mathrm{Co}_{5} \mathrm{NiS}_{8}\left(\mathrm{PEt}_{3}\right)_{6}{ }^{+}$species. Furthermore, according to the molecular orbital diagram of the clusters (Figure 2d), $\left[\mathrm{Co}_{5} \mathrm{FeS}_{8}\left(\mathrm{PEt}_{3}\right)_{6}\right]^{+}$contains an unpaired electron in its HOMO orbital. Collectively, these results rationalize the high propensity of $\left[\mathrm{Co}_{5} \mathrm{FeS}_{8}\left(\mathrm{PEt}_{3}\right)_{6}\right]^{+}$for oxidation in solution observed experimentally. 

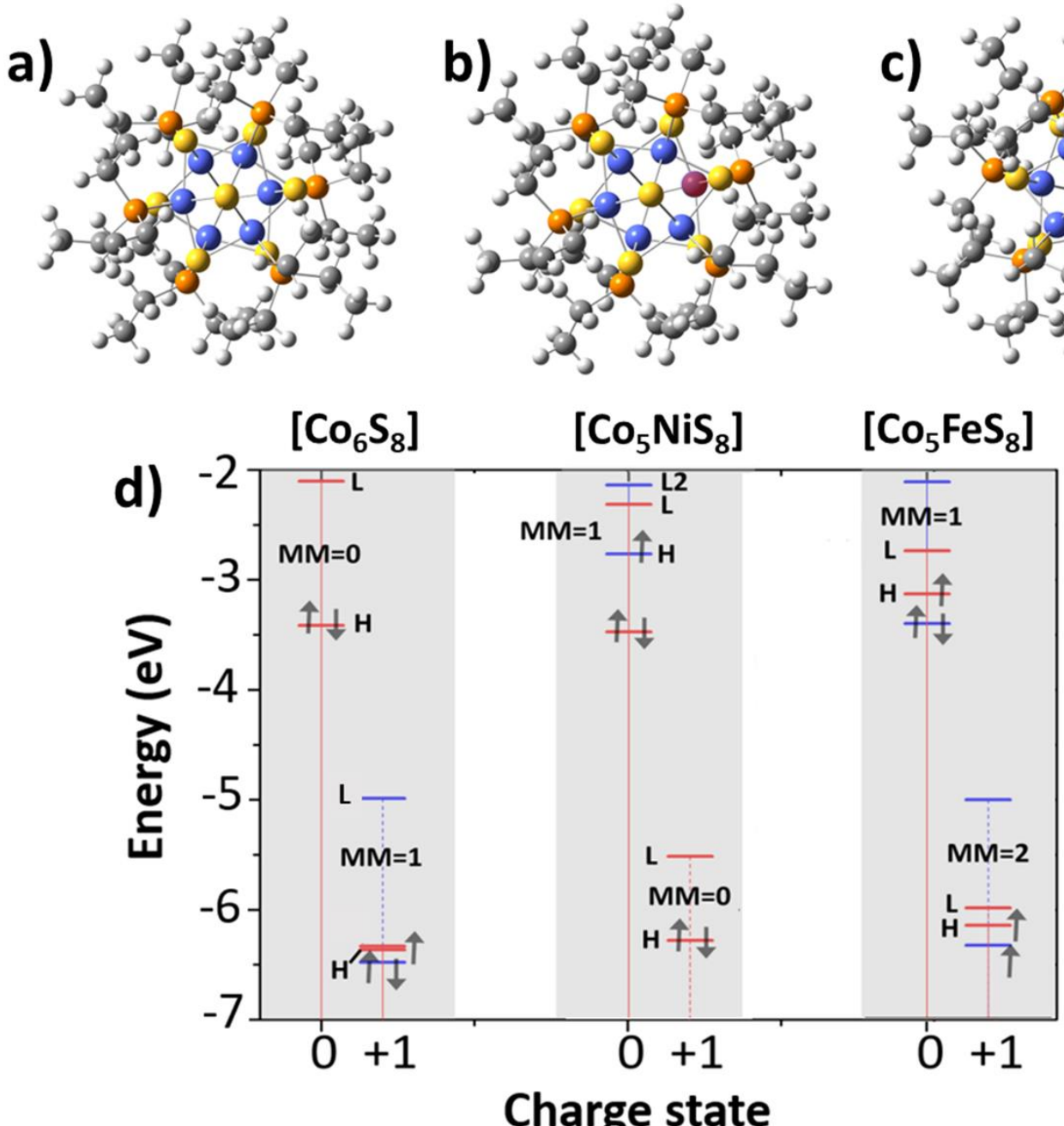

Figure 2. Optimized structures for the ground states of neutral (a) $\left[\mathrm{Co}_{6} \mathrm{~S}_{8}\left(\mathrm{PEt}_{3}\right)_{6}\right]$, (b) $\left[\mathrm{Co}_{5} \mathrm{NiS}_{8}\left(\mathrm{PEt}_{3}\right)_{6}\right]$, (c) $\left[\mathrm{Co}_{5} \mathrm{FeS}_{8}\left(\mathrm{PEt}_{3}\right)_{6}\right]$ clusters, (blue, purple, and black spheres correspond to Co, $\mathrm{Ni}$, and Fe atoms, respectively) (d) the calculated magnetic moments (MM) and HOMO-LUMO orbital arrangements of $\left[\mathrm{Co}_{6} \mathrm{~S}_{8}\left(\mathrm{PEt}_{3}\right)_{6}\right],\left[\mathrm{Co}_{5} \mathrm{NiS}_{8}\left(\mathrm{PEt}_{3}\right)_{6}\right]$ and $\left[\mathrm{Co}_{5} \mathrm{FeS}_{8}\left(\mathrm{PEt}_{3}\right)_{6}\right]$ in their 0 and +1 charge states. The arrows in each case show the spin state of the orbital. H and L stand for HOMO and LUMO orbitals, respectively. Red and blue lines indicate different spin states.

The calculated ionization energies for each cluster are summarized in Table 2. Although the first and second ionization energies of the $\mathrm{Co}_{5} \mathrm{FeS}_{8}\left(\mathrm{PEt}_{3}\right)_{6}$ are $\sim 0.3 \mathrm{eV}$ and $0.5 \mathrm{eV}$ lower than those of the unsubstituted cluster, Ni-substitution has an even more pronounced effect on the first and second ionization energies of the core lowering them by $0.6 \mathrm{eV}$ and $0.7 \mathrm{eV}$, respectively. Although these results indicate that it is easier to ionize both Fe- and Ni-substituted clusters in the gas phase, they do not rationalize their redox properties in solution as discussed earlier. This indicates that 
the ionization energy of the cluster is not a good predictor of its redox properties in solution. Is it also interesting that the ionization energy of $\left[\mathrm{Co}_{5} \mathrm{NiS}_{8}\left(\mathrm{PEt}_{3}\right)_{6}\right]$, namely $4.15 \mathrm{eV}$, is very close to that of Rubidium $(\mathrm{Rb}), 4.17 \mathrm{eV}$. Therefore, this cluster can be viewed as a superatom mimicking the chemistry of $\mathrm{Rb}$.

Table 2. The calculated ionization energies (IE), HOMO energy levels, and HOMOLUMO gaps of $\left[\mathrm{Co}_{6} \mathrm{~S}_{8}\left(\mathrm{PEt}_{3}\right)_{6}\right]$, $\left[\mathrm{Co}_{5} \mathrm{NiS}_{8}\left(\mathrm{PEt}_{3}\right)_{6}\right]$, and $\left[\mathrm{Co}_{5} \mathrm{FeS}_{8}\left(\mathrm{PEt}_{3}\right)_{6}\right]$ clusters in their 0 and +1 charged states given in $\mathrm{eV}$.

\begin{tabular}{cccc}
\hline \multicolumn{1}{c}{ Cluster } & IE & HOMO & HOMO-LUMO gap \\
\hline \hline$\left[\mathrm{Co}_{6} \mathrm{~S}_{8}\left(\mathrm{PEt}_{3}\right)_{6}\right]$ & 4.76 & -3.41 & 1.31 \\
{$\left[\mathrm{Co}_{5} \mathrm{NiS}_{8}\left(\mathrm{PEt}_{3}\right)_{6}\right]$} & 4.15 & -2.76 & 0.45 \\
{$\left[\mathrm{Co}_{5} \mathrm{FeS}_{8}\left(\mathrm{PEt}_{3}\right)_{6}\right]$} & 4.50 & -3.13 & 0.39 \\
{$\left[\mathrm{Co}_{6} \mathrm{~S}_{8}\left(\mathrm{PEt}_{3}\right)_{6}\right]^{+}$} & 12.49 & -6.36 & 1.45 \\
{$\left[\mathrm{Co}_{5} \mathrm{NiS}_{8}\left(\mathrm{PEt}_{3}\right)_{6}\right]^{+}$} & 11.79 & -6.27 & 0.16 \\
{$\left[\mathrm{Co}_{5} \mathrm{FeS}_{8}\left(\mathrm{PEt}_{3}\right)_{6}\right]^{+}$} & 12.01 & -6.15 & 0.76 \\
\hline
\end{tabular}

The calculated HOMO-LUMO gaps and electron configurations of the cluster cores provide insights into their optical and magnetic properties. The molecular orbital diagram of $\left[\mathrm{Co}_{5} \mathrm{FeS}_{8}\left(\mathrm{PEt}_{3}\right)_{6}\right]$ shown in Figure $2 \mathrm{~d}$ indicates the relatively small HOMO-LUMO gap in its neutral charge state and higher magnetic moments for this cluster in comparison with its unsubstituted counterpart. In contrast, although the neutral state of $\left[\mathrm{Co}_{5} \mathrm{NiS}_{8}\left(\mathrm{PEt}_{3}\right)_{6}\right]$ has the same magnetic moment as $\left[\mathrm{Co}_{5} \mathrm{FeS}_{8}\left(\mathrm{PEt}_{3}\right)_{6}\right]$, the spin states for its $\mathrm{HOMO}$ and LUMO are different. Thus, the optical transition between the HOMO and LUMO of $\mathrm{Co}_{5} \mathrm{NiS}_{8}\left(\mathrm{PEt}_{3}\right)_{6}$ is forbidden. The electronic transition is possible between the HOMO and the immediate orbital (L2 in Figure 2d) above LUMO, resulting in a larger energy gap for this cluster compared to $\mathrm{Co}_{5} \mathrm{Fe}\left(\mathrm{PEt}_{3}\right)_{6}$. On the other hand, unlike $\left[\mathrm{Co}_{5} \mathrm{FeS}_{8}\left(\mathrm{PEt}_{3}\right)_{6}\right]^{+}$, the +1 charge state of $\left[\mathrm{Co}_{5} \mathrm{NiS}_{8}\left(\mathrm{PEt}_{3}\right)_{6}\right]$ has a zero magnetic moment, leading to a much larger HOMO-LUMO gap. As shown in Figure $2 \mathrm{~d}$ and summarized in Table 2, the HOMO-LUMO gap of the neutral and cationic clusters decrease following the substitution of $\mathrm{Co}$ with $\mathrm{Ni}$ or Fe. These results reveal that substitution of a single $\mathrm{Co}$ atom in $\left[\mathrm{Co}_{6} \mathrm{~S}_{8}\left(\mathrm{PEt}_{3}\right)_{6}\right]$ with $\mathrm{Fe}$ or $\mathrm{Ni}$ has a pronounced effect on both the optical and magnetic properties 
of the clusters and shows the capability of atom-by-atom substitution for designing metal chalcogenide superatomic clusters with desired optical and magnetic properties.

The relative stability of the isolated $\left[\mathrm{Co}_{6} \mathrm{~S}_{8}\left(\mathrm{PEt}_{3}\right)_{6}\right]^{+},\left[\mathrm{Co}_{5} \mathrm{NiS}_{8}\left(\mathrm{PEt}_{3}\right)_{6}\right]^{+}$, and $\left[\mathrm{Co}_{5} \mathrm{FeS}_{8}\left(\mathrm{PEt}_{3}\right)_{6}\right]^{+}$ clusters towards fragmentation is examined in the gas phase using CID experiments performed at different collision energies in the range of $0-30 \mathrm{eV}$ on the QTOF-MS. The results are summarized in Figures 3(a-c). CID results indicate that a sequential loss of two ligands is a dominant dissociation pathway for all three cations. Interestingly, loss of the first ligand from $\left[\mathrm{Co}_{5} \mathrm{FeS}_{8}\left(\mathrm{PEt}_{3}\right)_{6}\right]^{+}$is observed at zero collision energy due to in-source fragmentation on the QTOF-MS system, which could not be completely suppressed by optimizing the source conditions. In contrast, a comparable extent of fragmentation is observed for $\left[\mathrm{Co}_{6} \mathrm{~S}_{8}\left(\mathrm{PEt}_{3}\right)_{6}\right]^{+}$and $\left[\mathrm{Co}_{5} \mathrm{NiS}_{8}\left(\mathrm{PEt}_{3}\right)_{6}\right]^{+}$at a collision energy of $20 \mathrm{eV}$. These results indicate that $\left[\mathrm{Co}_{5} \mathrm{FeS}_{8}\left(\mathrm{PEt}_{3}\right)_{6}\right]^{+}$ precursor is substantially less stable towards fragmentation in comparison with its $\left[\mathrm{Co}_{6} \mathrm{~S}_{8}\left(\mathrm{PEt}_{3}\right)_{6}\right]^{+}$ and $\left[\mathrm{Co}_{5} \mathrm{NiS}{ }_{8}\left(\mathrm{PEt}_{3}\right)_{6}\right]^{+}$counterparts.

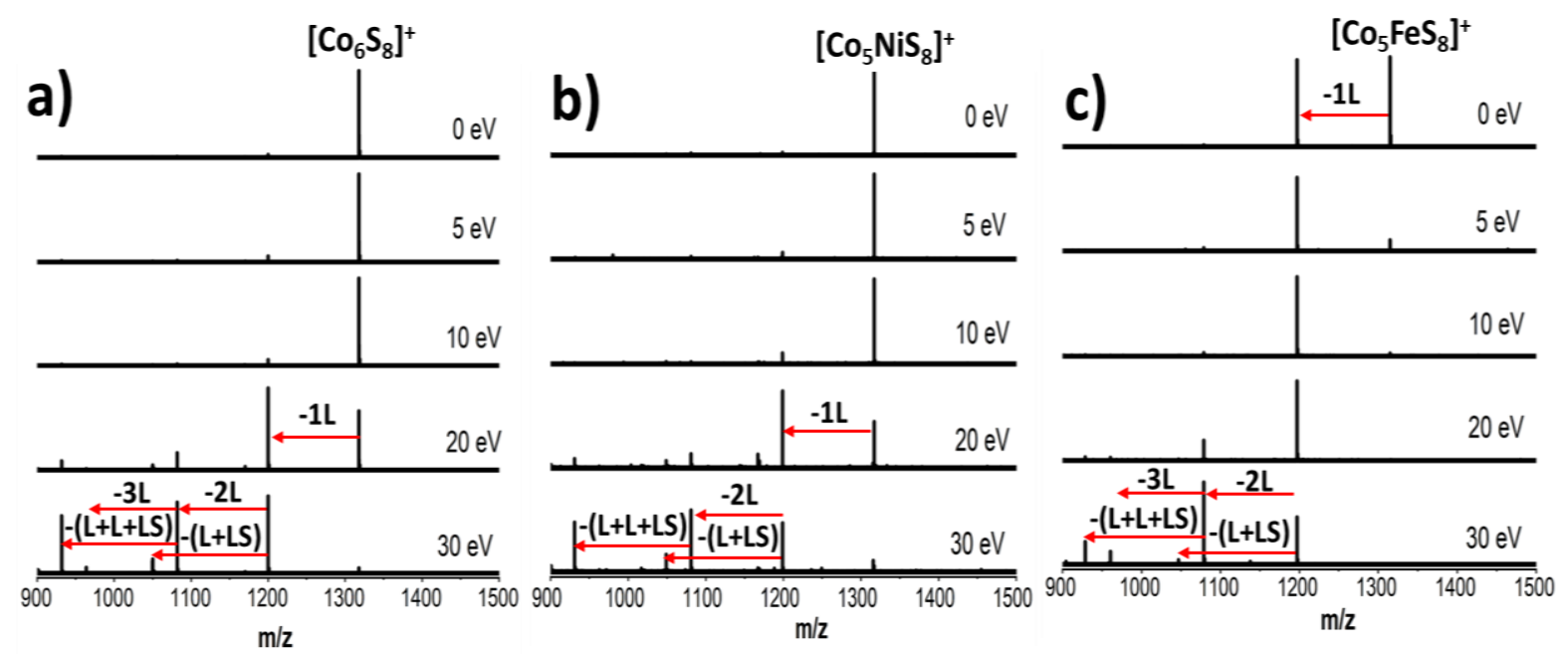

Figure 3. CID spectra at different collision energies acquired using QTOF MS for (a) $\left[\mathrm{Co}_{6} \mathrm{~S}_{8}\left(\mathrm{PEt}_{3}\right)_{6}\right]^{+}$, (b) $\left[\mathrm{Co}_{5} \mathrm{NiS}_{8}\left(\mathrm{PEt}_{3}\right)_{6}\right]^{+}$, and (c) $\left[\mathrm{Co}_{5} \mathrm{FeS}_{8}\left(\mathrm{PEt}_{3}\right)_{6}\right]^{+}$. Red arrows indicate sequential loss of ligand $\left(\mathrm{L}=\mathrm{PEt}_{3}\right)$ and ligand sulfide $(\mathrm{LS})$.

Another interesting observation is that ligand loss occurs in competition with the loss of ligand sulfide (LS), which is an unusual dissociation pathway, given that all the ligands are attached to metal atoms in the cluster. We observe the loss of LS from the precursor ion, along with sequential 
losses of "L+LS" and "L+L+LS". We find that the competition between the dissociation pathways is strongly dependent on the composition of the cluster core. We illustrate this dependence by comparing the breakdown graphs for the loss of the first three ligands along with LS, L+LS, and $\mathrm{L}+\mathrm{L}+\mathrm{LS}$ from the clusters in Figure 4. Although the loss of the first ligand from $\left[\mathrm{Co}_{5} \mathrm{FeS}_{8}\left(\mathrm{PEt}_{3}\right)_{6}\right]^{+}$ occurs at substantially lower collision energies than for $\left[\mathrm{Co}_{6} \mathrm{~S}_{8}\left(\mathrm{PEt}_{3}\right)_{6}\right]^{+}$and $\left[\mathrm{Co}_{5} \mathrm{NiS}_{8}\left(\mathrm{PEt}_{3}\right)_{6}\right]^{+}$, very similar breakdown curves are observed for all three precursor ions for the loss of the second ligand. These results can be rationalized assuming that the first ligand loss from $\left[\mathrm{Co}_{5} \mathrm{FeS}_{8}\left(\mathrm{PEt}_{3}\right)_{6}\right]^{+}$ involves cleavage of the Fe-P bond, which is likely a weaker bond in comparison with Co-P and Ni-P bonds. The resulting $\left[\mathrm{Co}_{5} \mathrm{FeS}_{8}\left(\mathrm{PEt}_{3}\right)_{5}\right]^{+}$fragment is more stable than its $\left[\mathrm{Co}_{6} \mathrm{~S}_{8}\right]$ and $\left[\mathrm{Co}_{5} \mathrm{NiS}_{8}\right]$ analogs, which shifts the breakdown curve for the second ligand loss from the $\left[\mathrm{Co}_{5} \mathrm{FeS}_{8}\right]$ species to higher collision energies, bringing it close to the curves obtained for the $\left[\mathrm{Co}_{6} \mathrm{~S}_{8}\right]$ and [Co5 $\left.\mathrm{NiS}_{8}\right]$ species. Loss of the third ligand is observed for $\left[\mathrm{Co}_{6} \mathrm{~S}_{8}\right]$ and $\left[\mathrm{Co}_{5} \mathrm{FeS}_{8}\right]$ but not for the $\left[\mathrm{Co}_{5} \mathrm{NiS}_{8}\right]$ species. Loss of the first LS in competition with the first ligand loss is observed exclusively for the $\left[\mathrm{Co}_{5} \mathrm{NiS}_{8}\right]$ precursor (Figure. $4 \mathrm{~d}$ ). Meanwhile, all three precursor ions undergo a minor $\mathrm{L}+\mathrm{LS}$ loss and abundant $\mathrm{L}+\mathrm{L}+\mathrm{LS}$ loss as seen in Figures $4 \mathrm{~d}$-f. These results indicate that the clusters become more fluxional and prone to rearrangement after the loss of two ligands.

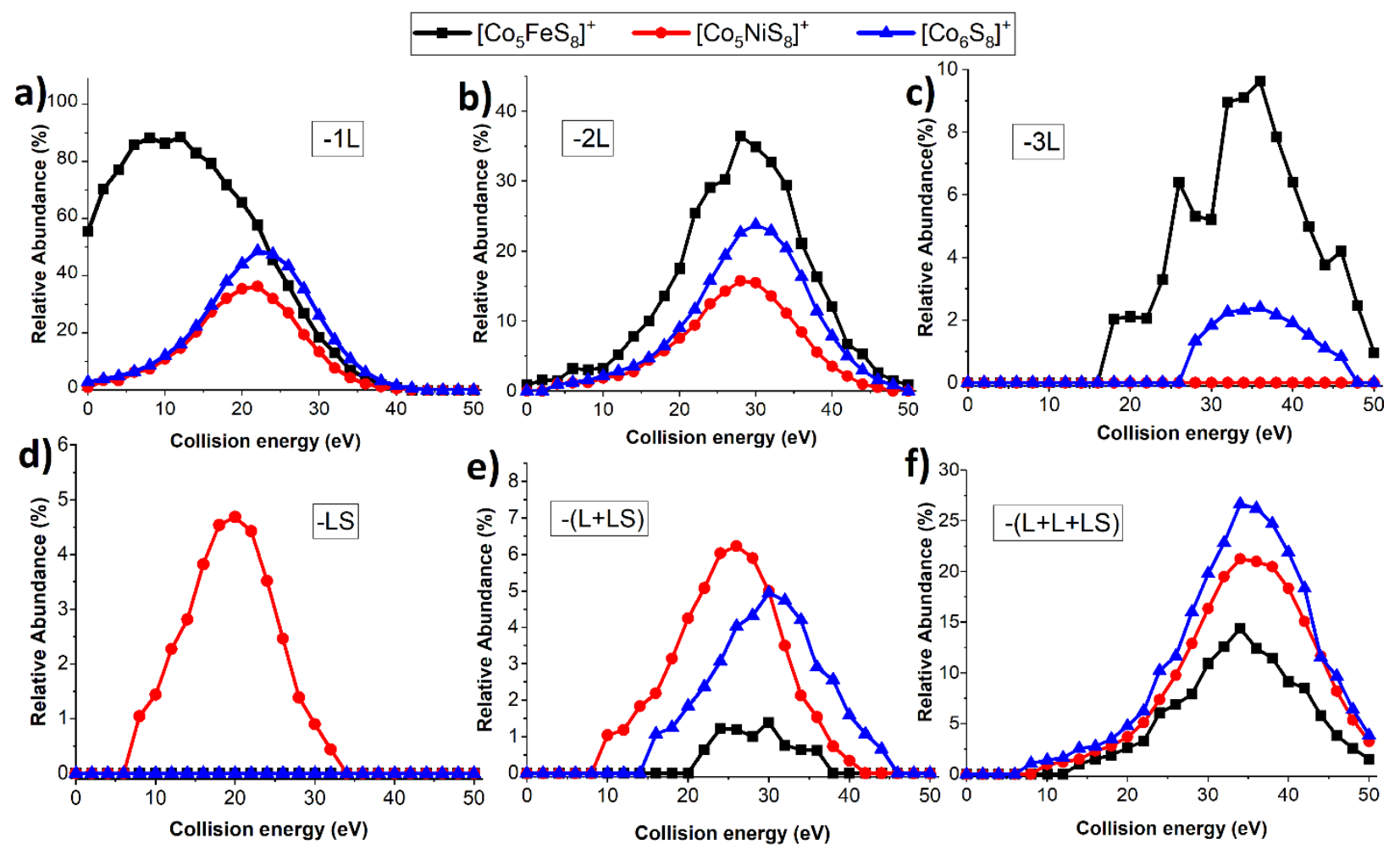


Figure 4. Comparison of (a-c) the first three ligand losses (1L, 2L, and $3 \mathrm{~L})$ and (d-f) the competing ligand sulfide losses (LS, L+LS, L+L+LS) from $\left[\mathrm{Co}_{6} \mathrm{~S}_{8}\left(\mathrm{PEt}_{3}\right)_{6}\right]^{+},\left[\mathrm{Co}_{5} \mathrm{NiS}_{8}\left(\mathrm{PEt}_{3}\right)_{6}\right]^{+}$and $\left[\mathrm{Co}_{5} \mathrm{FeS}_{8}\left(\mathrm{PEt}_{3}\right)_{6}\right]^{+}$, respectively.

In order to understand the observed differences in the fragmentation behavior of the clusters we compare the calculated bond lengths and vibrational frequencies of the modes involved in fragmentation in Table 3. The vibrational modes corresponding to the ligand and the sulfur atom vibrating radially against the metal atoms (Figure S7) are identified by analyzing the eigenvectors of the calculated vibrational modes. We observe that metal substitution has only a minor effect on the length of the $\mathrm{Co}^{-} \mathrm{S}$ and $\mathrm{Co}-\mathrm{P}$ bonds. Although both of the $\mathrm{Fe}-\mathrm{S}$ and $\mathrm{Ni}-\mathrm{S}$ bonds are longer than the $\mathrm{Co}-\mathrm{S}$ bond, these bond lengths are the same for $\mathrm{Fe}$ and $\mathrm{Ni}$ and independent of the charge state of the cluster. The most interesting changes with the type of metal and charge state are observed for the $\mathrm{Fe}-\mathrm{P}$ and $\mathrm{Ni}-\mathrm{P}$ bonds, which are associated with ligand losses. In particular, the longest metal-P bond of $2.251 \AA$ is observed for the $\left[\mathrm{Co}_{5} \mathrm{FeS}_{8}\left(\mathrm{PEt}_{3}\right)_{6}\right]^{+}$cluster. The observed elongation along with the lower frequency of the Fe-P is consistent with the high propensity of the ligand loss from the Fe-doped cluster. Furthermore, the vibrational frequency of the $\mathrm{Co}-\mathrm{S}$ bond in the Fe-substituted cluster is somewhat higher than the corresponding frequencies in both the unsubstituted and Ni-substituted cluster. This finding is consistent with the observed propensity of the ligand sulfide loss from the $\left[\mathrm{Co}_{5} \mathrm{NiS}_{8}\left(\mathrm{PEt}_{3}\right)_{6}\right]^{+}$cluster in CID experiments.

Table 3. Average bond lengths and vibrational frequencies of different bonds in both neutral and singly charge $\left[\mathrm{Co}_{6} \mathrm{~S}_{8}\left(\mathrm{PEt}_{3}\right)_{6}\right],\left[\mathrm{Co}_{5} \mathrm{NiS}_{8}\left(\mathrm{PEt}_{3}\right)_{6}\right]$ and $\left[\mathrm{Co}_{5} \mathrm{FeS}_{8}\left(\mathrm{PEt}_{3}\right)_{6}\right]$ clusters $\left(\mathrm{L}_{2}=\mathrm{PEt}_{3}\right)$.

\begin{tabular}{|c|c|c|c|c|c|c|c|}
\hline Clusters & $\begin{array}{l}M-S \\
(\AA) \\
\end{array}$ & $\begin{array}{l}\mathrm{Co}-\mathrm{S} \\
(\AA) \\
\end{array}$ & $\begin{array}{l}\text { M-P } \\
(\AA) \\
\end{array}$ & $\begin{array}{l}\mathrm{Co}-\mathrm{P} \\
(\AA) \\
\end{array}$ & $\begin{array}{l}\mathrm{Co}-\mathrm{P} \\
\left(\mathrm{cm}^{-1}\right) \\
\end{array}$ & $\begin{array}{l}\mathrm{L}-\mathrm{M} \\
\left(\mathrm{cm}^{-1}\right) \\
\end{array}$ & $\begin{array}{l}\mathrm{S}-\mathrm{Co} \\
\left(\mathrm{cm}^{-1}\right) \\
\end{array}$ \\
\hline$\left[\mathrm{Co}_{6} \mathrm{~S}_{8}\right]$ & -- & 2.242 & -- & 2.144 & 598.6 & -- & 373.0 \\
\hline $\begin{array}{l}{\left[\mathrm{Co}_{5} \mathrm{MS}_{8}\right]} \\
\mathrm{M}=\mathrm{Fe}\end{array}$ & 2.263 & 2.243 & 2.174 & 2.150 & 597.8 & 584.8 & 375.7 \\
\hline $\begin{array}{l}{\left[\mathrm{Co}_{5} \mathrm{NS}_{8}\right]} \\
\mathrm{M}=\mathrm{Ni}\end{array}$ & 2.267 & 2.242 & 2.289 & 2.148 & 598.6 & 582.3 & 370.5 \\
\hline$\left[\mathrm{Co}_{6} \mathrm{~S}_{8}\right]^{+}$ & -- & 2.235 & -- & 2.176 & 599.3 & -- & 379.4 \\
\hline $\begin{array}{c}{\left[\mathrm{Co}_{5} \mathrm{MS}_{8}\right]^{+},} \\
\mathrm{M}=\mathrm{Fe}\end{array}$ & 2.261 & 2.232 & 2.251 & 2.178 & 598.8 & 589.3 & 377.7 \\
\hline $\begin{array}{l}{\left[\mathrm{Co}_{5} \mathrm{MS}_{8}\right]^{+},} \\
\mathrm{M}=\mathrm{Ni}\end{array}$ & 2.260 & 2.234 & 2.205 & 2.163 & 600.3 & 591.1 & 376.0 \\
\hline
\end{tabular}


The decrease in the ligand binding energy in the Fe-substituted cluster indicates that Fe-doping may be a good strategy for generating under-coordinated metal centers for catalytic applications by ligand stripping. In contrast, the electron-rich $\left[\mathrm{Co}_{5} \mathrm{NiS}_{8}\left(\mathrm{PEt}_{3}\right)_{6}\right]^{+}$cluster is prone to rearrangement resulting in the loss of LS from the cluster.

\section{Conclusions}

In this study, we synthesized superatomic clusters by substituting Co atoms in the core of a well-defined cobalt sulfide superatom, $\left[\mathrm{Co}_{6} \mathrm{~S}_{8}\left(\mathrm{PEt}_{3}\right)_{6}\right]^{+}$, with $\mathrm{Fe}$ and Ni. The properties of the doped clusters were investigated using mass spectrometry and electronic structure calculations. Experimental and computational studies indicate that $\mathrm{Fe}$ and $\mathrm{Ni}$-heteroatoms have different impact on the electronic structure as well as core-ligand interaction of the cluster. We observe efficient $\mathrm{Fe}$ substitution into the core generating a distribution of clusters with 1-6 Fe atoms in the core. ESIMS indicates that these clusters undergo oxidation in solution and generate stable doubly charged species. In contrast, only a single $\mathrm{Ni}$ atom could be substituted into the $\left[\mathrm{Co}_{6} \mathrm{~S}_{8}\right]$ core and the resulting cluster is stable in solution as a singly charged species, $\left[\mathrm{Co}_{5} \mathrm{NiS}_{8}\left(\mathrm{PEt}_{3}\right)_{6}\right]^{+}$. Computational studies reveal that $\left[\mathrm{Co}_{5} \mathrm{FeS}_{8}\left(\mathrm{PEt}_{3}\right)_{6}\right]^{+}$has a higher $\mathrm{HOMO}$ level and an unpaired electron in the HOMO as compared to both the unsubstituted and Ni-substituted analogs, which rationalizes its high propensity for losing the second electron. Furthermore, CID experiments indicate that Fesubstitution substantially reduces the stability of the cluster towards ligand loss. Computational results show that the $\mathrm{Fe}-\mathrm{P}$ bond is elongated and the corresponding vibrational frequency is somewhat lower in comparison with both $\mathrm{Co}-\mathrm{P}$ and $\mathrm{Ni}-\mathrm{P}$ bonds, which explains the lower stability of the $\left[\mathrm{Co}_{5} \mathrm{FeS}_{8}\left(\mathrm{PEt}_{3}\right)_{6}\right]^{+}$cation towards ligand loss. Theoretical calculations provide insights into the effect of atom-by-atom substitution on the magnetic and optical properties of the clusters, which will be further explored in future studies. Our results demonstrate that atom-by-atom substitution strategy applied to metal chalcogenide clusters is a promising approach for designing new superatomic clusters with tailored electronic, magnetic, and optical properties. 


\section{Experimental}

\section{Chemicals}

Cobalt (II) chloride, $\mathrm{CoCl}_{2}$, (97\%), Nickel (II) chloride, $\left(\mathrm{NiCl}_{2}\right)$ (99.99\%), Iron (II) chloride tetrahydrate, $\mathrm{FeCl}_{2} .4 \mathrm{H}_{2} \mathrm{O}$, (99\%), Sodium sulfide nonahydrate, $\mathrm{Na}_{2} \mathrm{~S} .9 \mathrm{H}_{2} \mathrm{O}$, (98\%) and Triethylphosphine (99\%) were purchased from Sigma-Aldrich. Methanol (HPLC grade) was purchased from Sigma-Aldrich and used without any purification.

\section{Synthesis of cobalt sulfide cluster ligated with $\mathrm{PEt}_{3},\left[\mathrm{Co}_{6} \mathrm{~S}_{8}\left(\mathrm{PEt}_{3}\right)_{6}\right]^{+}$}

Cobalt sulfide cluster ligated with $\mathrm{PEt}_{3},\left[\mathrm{Co}_{6} \mathrm{~S}_{8}\left(\mathrm{PEt}_{3}\right)_{6}\right]^{+}$, is synthesized by dissolving $0.016 \mathrm{~g}$ $(0.124 \mathrm{mmol})$ of $\mathrm{CoCl}_{2}$ in $3.75 \mathrm{~mL}$ of methanol. $147.6 \mu \mathrm{L}(1 \mathrm{mmol})$ of $\mathrm{PEt}_{3}$ added to the dissolved $\mathrm{CoCl}_{2}$ solution under the inert atmosphere in a nitrogen box (830ABB, PLAS LABS) and mixed for $10 \mathrm{~min}$. The molar ratio of $\mathrm{PEt}_{3}$ to $\mathrm{CoCl}_{2}$ is $8: 1$. Next, $0.15 \mathrm{~g} \mathrm{Na}_{2} \mathrm{~S}_{2} 9 \mathrm{H}_{2} \mathrm{O}$ dissolved in $2 \mathrm{~mL}$ of methanol is added to the stirred solution one drop at a time and generates a dark brown solution. The photographs of the solution at each step of this synthesis are shown in Fig.S1. The final solution is stirred for several days outside the nitrogen box at room temperature and the reaction is followed using mass spectrometry.

\section{Synthesis of $\mathrm{Fe}$ and $\mathrm{Ni}$ atom substituted cobalt cluster, $\left[\mathrm{Cos}_{1} \mathrm{M}_{1} \mathrm{~S}_{8}\left(\mathrm{PEt}_{3}\right)_{6}\right]^{+}, \mathrm{M}=\mathrm{Fe}, \mathrm{Ni}$}

Fe-substituted cobalt sulfide clusters, $\left[\mathrm{Co}_{5} \mathrm{FeS}_{8}\left(\mathrm{PEt}_{3}\right)_{6}\right]^{+}$, are synthesized using high and low molar ratio of doping atom, $\mathrm{Fe}$, to $\mathrm{Co}$ in order to understand how different ratio of doping atoms affects the distribution of the final products. For the synthesis of the $\left[\mathrm{Co}_{5-\mathrm{x}} \mathrm{Fe}_{\mathrm{x}} \mathrm{S}_{8}\left(\mathrm{PEt}_{3}\right)_{6}\right]^{+}$with 1:1 ratio of metal precursors which is considered as high molar ratio of doping atom, $0.016 \mathrm{~g}(0.124$ $\mathrm{mmol})$ of $\mathrm{CoCl}_{2}$ and $0.0246 \mathrm{~g}(0.124 \mathrm{mmol})$ of $\mathrm{FeCl}_{2} .4 \mathrm{H}_{2} \mathrm{O}$ are dissolved in $3.75 \mathrm{ml}$ methanol and $147.6 \mu \mathrm{L}(1 \mathrm{mmol})$ of $\mathrm{PEt}_{3}$ is added to the solution under the inert atmosphere using standard glovebox. The solution is stirred for $10 \mathrm{~min}$. Then $0.15 \mathrm{~g} \mathrm{Na}_{2} \mathrm{~S}_{2} 9 \mathrm{H}_{2} \mathrm{O}$ dissolved in $2 \mathrm{ml}$ methanol and subsequently is added to the stirring solution one drop at a time. The final solution mixed for several days outside the glovebox at room temperature and the reaction followed by mass spectrometer. Fe-substituted cluster with 6:1 molar ratio of Co to Fe which is considered low ratio of dopant metal is also synthesized with the same procedure. The same procedure is also used for 
the synthesis of the Ni-substituted cobalt sulfide cluster, $\left[\mathrm{Co}_{5} \mathrm{NiS}_{8}\left(\mathrm{PEt}_{3}\right)_{6}\right]^{+}$, with high and low molar ratio of $\mathrm{CoCl}_{2}$ and $\mathrm{NiCl}_{2}$.

\section{Mass spectrometry and collision-induced dissociation experiments}

Mass spectrometry experiments are performed using an Agilent 6560 ion mobility quadrupole time-of-flight (IM QTOF, Agilent technologies, CA) and a linear ion trap mass spectrometer (LTQ XL, Thermo Fisher Scientific, Waltham, MA). Samples are diluted in methanol to a $\sim 3-5 \mu \mathrm{M}$ concentration and analyzed using a custom-designed electrospray ionization source operated in positive ion mode. In these experiments, samples are delivered to a mass spectrometer inlet by a

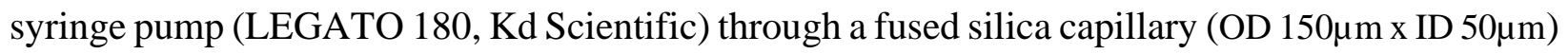
at a flow rate of $0.12 \mu \mathrm{L} / \mathrm{min}$ and ionized by applying a high voltage of $3.5 \mathrm{kV}$ either to the instrument's inlet (QTOF) or to the syringe needle (LTQ). Collision-energy resolved CID experiments are performed on the QTOF using nitrogen as a collision gas, the isolation window of $1.3 \mathrm{~m} / \mathrm{z}$, and with collision energies ranging from $0-30 \mathrm{eV}$.

\section{Theoretical Methods}

All calculations are carried out using density functional theory (DFT) with the PBE functional ${ }^{[33]}$. Determining the equilibrium geometries of pure and $\mathrm{Fe}, \mathrm{Ni}$ doped $\mathrm{Co}_{6} \mathrm{~S}_{8}\left(\mathrm{PEt}_{3}\right)_{6}$ clusters are computational demanding tasks as the cluster contains 98 atoms. In addition, because of the 6 transition metal atoms, the cluster can also be magnetic. Thus, to obtain equilibrium geometries, one not only has to optimize the structure without any symmetry constraint, but also carry this out for every possible spin configuration. We used two different techniques - one based on reciprocal space method and the other on the real space method. For the former, we used the Vienna Ab initio Simulation package (VASP) ${ }^{[34],[35]}$ with plane-wave basis states. For the latter, we used the Gaussian $16^{[36]}$ package with Gaussian basis sets. First, computationally more efficient VASP code is used to optimize the geometries and the magnetic moments of the ligated pure Co and Fe- and Ni-substituted clusters with zero and +1 charge state. The total energy and force are set at $1 \times 10^{-}$ ${ }^{4} \mathrm{eV}$ and $0.01 \mathrm{eV} / \AA$, respectively. Second, the optimized geometries obtained from VASP calculations were used as starting configuration in the Gaussian16 code and further optimization, keeping the same magnetic ground state. The Karlsruhe Def2-TVZP basis sets are used for the metal elements and $6-311+\mathrm{G}(\mathrm{d}, \mathrm{p})$ basis sets are used for the non-metal elements. To ensure the 
accuracy of the calculated ionization energy, we used Gaussian to reoptimize the structures of the clusters and calculate the energies of $0,+1$ and +2 charge states for each case. The vibrational frequencies are computed using Gaussian, based on the reoptimized geometry structures.

\section{Acknowledgments}

Part of this research was supported by the Purdue Research Foundation (PRF) research grant. P. J. acknowledges partial supported from the U.S. Department of Energy, Office of Basic Energy Sciences, Division of Materials Sciences and Engineering under Award No.DE-FG0296ER45579.

\section{References}

[1] Y. Cao, J. Guo, R. Shi, G. I. N. Waterhouse, J. Pan, Z. Du, Q. Yao, L. Z. Wu, C. H. Tung, J. Xie, T. Zhang, Nat. Commun. 2018, 9, 2379.

[2] A. P. Aydt, B. Qie, A. Pinkard, L. Yang, Q. Cheng, S. J. L. Billinge, Y. Yang, X. Roy, ACS Appl. Mater. Interfaces. 2019, 11, 11292.

[3] A. S. Urban, X. Shen, Y. Wang, N. Large, H. Wang, M. W. Knight, P. Nordlander, H. Chen, N. J. Halas, Nano Lett. 2013, 13, 4399.

[4] T. Pradeep, ACS Omega. 2017, 2, 7576.

[5] A. W. Castleman, P. Jena, Prog. Nat. Sci. Mater. Int. 2006, 103, 10554.

[6] D. M. Black, N. Bhattarai, R. L. Whetten, S. B. H. Bach, J. Phys. Chem. A. 2014, 118, 10679.

[7] P. Jena, Q. Sun, Chem. Rev. 2018, 118, 5755.

[8] G. Liu, V. Chauhan, A. P. Aydt, S. M. Ciborowski, A. Pinkard, Z. Zhu, X. Roy, S. N. Khanna, K. H. Bowen, J. Phys. Chem. C. 2019, 123, 25121.

[9] J. Yan, H. Su, H. Yang, S. Malola, S. Lin, N. Zheng, J. Am. Chem. Soc. 2015, 137, 11880.

[10] A. Ghosh, O. F. Mohammed, O. M. Bakr, Acc. Chem. Res. 2018, 51, 3094.

[11] J. Yang, R. Jin, ACS Mater. Lett. 2019, 1, 482.

[12] A. Ghosh, T. Pradeep, Eur. J. Inorg. Chem. 2014, 5271.

[13] L. Liao, S. Zhou, Y. Dai, L. Liu, C. Yao, C. Fu, J. Yang, Z. Wu, J. Am. Chem. Soc. 2015, $137,9511$.

[14] Q. Li, M. G. Taylor, K. Kirschbaum, K. J. Lambright, X. Zhu, G. Mpourmpakis, R. Jin, J. Colloid Interface Sci. 2017, 505, 1202. 
[15] M. S. Bootharaju, C. P. Joshi, M. R. Parida, O. F. Mohammed, O. M. Bakr, Angew. Chemie - Int. Ed. 2016, 55, 922.

[16] I. Chakraborty, T. Pradeep, Chem. Rev. 2017, 117, 8208.

[17] R. Jin, J. Amercian Chem. Soc. 2012, 24, 10.

[18] M. B. Freeman, L. Wang, D. S. Jones, C. M. Bejger, J. Mater. Chem. Aournal Mater. Chem. A. 2018, 6, 21927.

[19] X. Roy, C. Lee, A. C. Crowther, L. Christine, T. Besara, R. A. Lalancette, T. Siegrist, W. Stephens, L. E. Brus, P. Kim, M. L. Steigerwald, C. Nuckolls , Science. 2013, 432, 157.

[20] V. Chauhan, A. C. Reber, S. N. Khanna, J. Am. Chem. Soc. 2017, 139, 1871-1877.

[21] A. P. Aydt, B. Qie, A. Pinkard, L. Yang, Q. Cheng, S. J. L. Billinge, Y. Yang, X. Roy, ACS Appl. Mater. Interfaces. 2019, 11, 11292.

[22] J. Yu, C. Lee, D. Bouilly, M. Han, P. Kim, M. L. Steigerwald, X. Roy, C. Nuckolls, Nano Lett. 2016, 16, 3385.

[23] A. Pinkard, A. M. Champsaur, X. Roy, Acc. Chem. Res. 2018, 51, 919.

[24] G. Lovat, B. Choi, D. W. Paley, M. L. Steigerwald, L. Venkataraman, X. Roy, Nat. Nanotechnol. 2017, 12, 1050.

[25] E. A. Doud, X. Roy, C. Nuckolls, Nat. Rev. 2020, 5, 371.

[26] A. C. Reber, D. Bista, V. Chauhan, S. N. Khanna, J. Phys. Chem. C. 2019, 123, 8983.

[27] A. O. Franco Cecconi, Carlo A.Ghilardi, Stefano Midollini, Polyhedron. 1986, 5, 706.

[28] C. A. Goddard, J. R. Long, R. H. Holm, Inorg. Chem. 1996, 35, 4347.

[29] C. A. G. and S. M. Franco Cecconi, J. Chem. Soc. Chem. Commun. 1981, 640.

[30] A. V. Anyushin, E. V. Korotaev, A. Yu. Andreeva, M. R. Ryzhikov, D. A. Mainichev, M. N. Sokolov, Russ. Chem. Bull. Int. Ed. 2016, 65, 173.

[31] A. V Anyushin, M. N. Sokolov, A. V Virovets, N. F. Zakharchuk, D. A. Mainichev, V. P. Fedin, Inorg. Chem. Commun. 2012, 24, 225.

[32] I. Dance, Inorg. Chem. 2006, 45, 5084.

[33] W. C. Frisch, M. J.; Trucks, G. W.; Schlegel, H. B.; Scuseria, G. E.; Robb, M. A.; Cheeseman, J. R.; Scalmani, G.; Barone, V.; Petersson, G. A.; Nakatsuji, H.; Li, X.; Caricato, M.; Marenich, A. V.; Bloino, J.; Janesko, B. G.; Gomperts, R.; Mennucci, B.; Hratch, Gaussian 16, Revis. C.01 2016.

[34] G. Kresse, J. Furthmiiller, Comput. Mater. Sci. 1996, 6, 15.

[35] G. Kresse, J. Furthmu, Phys. Rev. B. 1996, 54, 11169.

[36] W. C. Frisch, M. J.; Trucks, G. W.; Schlegel, H. B.; Scuseria, G. E.; Robb, M. A.; 
Cheeseman, J. R.; Scalmani, G.; Barone, V.; Petersson, G. A.; Nakatsuji, H.; Li, X.; Caricato, M.; Marenich, A. V.; Bloino, J.; Janesko, B. G.; Gomperts, R.; Mennucci, B.; Hratch, 2016. 